\title{
Maternal protein restriction in mice causes adverse metabolic and hypothalamic effects in the F1 and F2 generations
}

\author{
Nayara Peixoto-Silva, Eliete Dalla Corte Frantz, Carlos Alberto Mandarim-de-Lacerda \\ and Alessandra Pinheiro-Mulder* \\ Laboratory of Morphometry and Cardiovascular Morphology, Biomedical Center, Institute of Biology, State University of \\ Rio de Janeiro, Rio de Janeiro, Brazil
}

(Received 23 July 2010 - Revised 4 March 2011 - Accepted 7 March 2011 - First published online 31 May 2011)

\begin{abstract}
Maternal protein restriction causes metabolic alterations associated with hypothalamic dysfunction. Because the consequences of metabolic programming can be passed transgenerationally, the present study aimed to assess whether maternal protein restriction alters the expression of hypothalamic neuropeptides in offspring and to evaluate hormonal and metabolic changes in male offspring from the F1 and F2 generations. Female Swiss mice (F0) were mated and fed either a normal-protein (NP group; 19\% protein) or a low-protein (LP group; $5 \%$ protein) diet throughout gestation of the F1 generation (NP1 and LP1). At 3 months of age, F1 females were mated to produce the F2 generation (NP2 and LP2). Animals from all groups were evaluated at 16 weeks of age. LP1 offspring had significantly lower weights and shorter lengths than NP1 offspring at birth, but they underwent a phase of rapid catch-up growth. Conversely, the LP2 offspring were not significantly different from the NP2 offspring in either weight or length. At 16 weeks, no differences were found in body mass among any of the groups, although LP1 and LP2 offspring showed hypercholesterolaemia, hypertriacylglycerolaemia, hyperglycaemia, glucose intolerance, insulin resistance, increased levels of insulin, leptin and resistin, decreased endogenous leptin sensitivity, increased adiposity with elevated leptin levels and leptin resistance characterised by altered expression of neuropeptide $\mathrm{Y}$ and pro-opiomelanocortin without any changes in the leptin receptor Ob-Rb. We conclude that severe maternal protein restriction promotes metabolic programming in F1 and F2 male offspring due to a dysregulation of the adipoinsular axis and a state of hypothalamic leptin resistance.
\end{abstract}

Key words: Maternal protein restriction: Leptin: Neuropeptides: Obesity: Catch-up growth

The tendency towards obesity may begin very early in life ${ }^{(1)}$. The increasing worldwide incidence of obesity in the last decade has led to a need to define and understand the physiological mechanisms that predispose individuals to gain weight in infancy, childhood and adulthood ${ }^{(2)}$. Furthermore, exposure to an inappropriate level of nutrition during prenatal and/or postnatal development can have significant implications for the ability of an individual to regulate their body weight after birth, which can predispose one to obesity later in life $\mathrm{l}^{(3,4)}$.

Different experimental protocols altering the maternal diet have been developed to understand the changes involved in the neuroendocrine control of body weight. In maternal obesity models, pups develop leptin resistance and the components of intracellular signalling are altered as a result of the intra-uterine environment combined with an inadequate postnatal diet ${ }^{(1,5,6)}$. Similarly, maternal malnutrition also influences hypothalamic development, in that restricted maternal diets result in a neonatal leptin surge that is able to disrupt the hypothalamic anorexigenic pathway ${ }^{(7,8)}$. The literature further demonstrates that permanent hypothalamic dysfunction can result from changes in gene expression related to energetic homeostasis with maternal protein restriction during fetal development and/or early postnatal life ${ }^{(9)}$. Other consequences may also be related to alterations in the neonatal leptin surge ${ }^{(10)}$, as leptin plays a fundamental role in the development of regulatory circuits in the early postnatal

Abbreviations: BM, body mass; F0, maternal generation; F1, first generation; F2, second generation; HOMA- $\beta$, homeostatic model assessment of $\beta$-cell function; HOMA-IR, homeostatic model assessment of insulin resistance; HRP, horseradish peroxidase; IPITT, intraperitoneal insulin tolerance test; LP1, low-protein diet first generation; LP2, low-protein diet second generation; $\alpha$-MSH, $\alpha$-melanocyte-stimulating hormone; NAL, naso-anal length; NP1, normal-protein diet first generation; NP2, normal-protein diet second generation; NPY, neuropeptide Y; Ob-Rb, leptin receptor; OGTT, oral glucose tolerance test; POMC, pro-opiomelanocortin.

* Corresponding author: Professor Dr Alessandra Pinheiro-Mulder, fax +55 212587 6133, email pinheiromulder@uerj.br 
lives of rodents beyond the control of food behaviour later in life ${ }^{(11,12)}$.

Energy balance is regulated by feedback from peripheral hormonal and metabolic signals on the central integrating circuits, which are concentrated in the hypothalamus and primarily expressed in the arcuate nucleus ${ }^{(13)}$. This hypothalamic neural network integrates signals that relate energy supply, energy utilisation and total energy reserves to appropriately regulate food intake and energy expenditure, thus maintaining energy balance ${ }^{(14)}$. Leptin, a major signal for energy balance, is derived from adipose tissue ${ }^{(15)}$ and is considered very important in the activation of the hypothalamic nuclei. Leptin signalling primarily conveys information about the size of the body's energy reserves and thus provides negative feedback on food intake ${ }^{(16)}$.

Leptin acts at hypothalamic receptors, mainly the leptin receptor $\mathrm{Ob}-\mathrm{Rb}$, to initiate a signalling cascade through effectors such as Janus kinase/signal transducers and activators of transcription factors (JAK/STAT) ${ }^{(17)}$. Once phosphorylated, STAT-3 is transported into the nucleus to alter the gene expression of neurotransmitters that are responsive to hormones $^{(18)}$.

Orexigenic effects are the result of the action of neuropeptide Y (NPY) at specific receptors ${ }^{(19)}$ and Agouti-related peptide (AgRP) binding at melanocortin receptors. Conversely, pro-opiomelanocortin (POMC) processing produces $\alpha$-melanocyte-stimulating hormone ( $\alpha$-MSH), which promotes anorexigenic effects by acting at the same melanocortin receptors ${ }^{(20)}$. Therefore, leptin signalling via Ob-Rb stimulates the production of neuropeptides that are responsible for the suppression of food intake, and inhibit the expression of orexigenic peptides in the arcuate nucleus ${ }^{(21)}$.

In a previous study, we observed intriguing experimental evidence to suggest that altered glucose metabolism and body composition were passed from the F1 to the F2 generation when F0 mothers were fed a protein-restricted diet ${ }^{(22)}$. To follow up on this observation, the present study aimed to first assess whether maternal protein restriction alters the expression of a panel of neuropeptides that have been implicated in hypothalamic leptin signalling. The present study also sought to evaluate peripheral hormonal and metabolic changes in the mature male offspring from the F1 and F2 generations.

\section{Experimental methods}

\section{F1 generation}

A total of ten 8-week-old, virgin, female Swiss mice (F0) were maintained under a $12 \mathrm{~h}$ light $-12 \mathrm{~h}$ dark cycle (artificial light from 00.00 to 12.00 hours) in a room with controlled temperature $\left(21 \pm 2^{\circ} \mathrm{C}\right)$ and humidity $(60 \pm 10 \%)$. All procedures were performed in accordance with the Guide for the Care and Use of Laboratory Animals (US National Institutes of Health 85-23, revised 1996) and approved by the Animal Ethics Committee at the Biology Institute of the State University of Rio de Janeiro.
Females (F0) were mated with proven male breeders, and the day on which spermatozoa were present in a vaginal smear was designated as the day of conception (day 0). Pregnant mice were then isolated and randomly assigned to one of two groups; one group was fed a normal-protein diet (NP group; $19 \%$ protein; $n$ 5), and the other was fed a low-protein diet (LP group; $5 \%$ protein; $n$ 5) (diets were produced by Prag Soluções, Jau, SP, Brazil). The two diets were isoenergetic $(1900 \mathrm{~kJ} / 100 \mathrm{~g})$, and the low-protein diet was compensated for energy by the addition of carbohydrates (starch). The mineral and vitamin content of both diets was identical and in accordance with the recommendations of the American Institute of Nutrition (AIN-93) ${ }^{(23)}$.

When F0 mothers gave birth to the F1 generation, the pups were weighed and the litter size was recorded. After delivery, F0 mothers from both groups were fed the NP diet. To standardise the food supply, litters were adjusted to six pups per litter (if possible, a 1:1 sex ratio was maintained; ano-genital distance was used to determine sex). The pups were raised until weaning, after which one male pup per litter was randomly assigned to each of the F1 groups (NP1 and LP1).

\section{F2 generation}

F1 females aged 8 weeks old (five per group) were mated to proven male breeders from outside the study, producing the F2 generation (NP2 and LP2). The F1 females were fed the NP diet during pregnancy, and the same procedures described for the F1 generation were used to obtain the F2 groups of males.

\section{Biometry and food intake after weaning}

Body mass (BM) and naso-anal length (NAL) were measured weekly. Daily food consumption was measured as the difference between the amount of food provided and the amount of food remaining $24 \mathrm{~h}$ later. Food intake was not only recorded in absolute terms but was also adjusted for BM $((\mathrm{g} \mathrm{food} / \mathrm{g} \mathrm{BM}) \times 100)$.

\section{Metabolic profile}

An oral glucose tolerance test (OGTT) was performed at week 15. After a $6 \mathrm{~h}$ fasting period, $25 \%$ glucose was administered in sterile saline $(0.9 \% \mathrm{NaCl})$ by oral administration at the dose of $1 \mathrm{~g} / \mathrm{kg}$ BM. Blood was drawn from the tip of each animal's tail to measure plasma glucose concentrations, which were assessed with a glucometer (Accu-Chek Go; Roche Diagnostics, Mannheim, Germany) before glucose administration and at 15, 30, 60 and 120 min after administration ${ }^{(24,25)}$. In addition, an intraperitoneal insulin tolerance test (IPITT) was performed at week 16. After $4 \mathrm{~h}$ fasting, insulin was injected intraperitoneally $(34.1 \mu \mathrm{g}(0.75 \mathrm{IU}) / \mathrm{kg}$ BM). As described above, plasma glucose concentrations were measured before insulin injection and at 15, 30, 60 and $120 \mathrm{~min}$ after injection ${ }^{(25)}$. The area under the curve was calculated for both tests using the trapezoid rule to assess glucose intolerance (OGTT) and insulin resistance (IPITT). 


\section{Euthanasia}

F1 and F2 offspring were raised to an age of 16 weeks. Before euthanasia, the animals were heparinised and deeply anaesthetised with intraperitoneal sodium pentobarbital $(150 \mathrm{mg} / \mathrm{kg} \mathrm{BM})$ after a $6 \mathrm{~h}$ fast. Blood was collected by cardiac puncture from the right atrium.

Brains were rapidly harvested, and hypothalami were dissected using the optic tracts, lateral sulci, mammillary bodies and thalamus as landmarks ${ }^{(26,27)}$. After dissection, each hypothalamus was immediately frozen on dry ice and then stored at $-80^{\circ} \mathrm{C}$ for further molecular analyses. Retroperitoneal, epididymal and subcutaneous fat pads were also removed, weighed, rapidly frozen and stored at $-80^{\circ} \mathrm{C}$ for further molecular analyses. The subcutaneous fat:visceral fat ratio was calculated as inguinal fat mass/epididymal and retroperitoneal fat masses. Adipose tissue was fixed for $48 \mathrm{~h}$ at room temperature in freshly prepared fixative $(1.27 \mathrm{M}$-formaldehyde in $0 \cdot 1 \mathrm{~m}$-phosphate buffer; $\mathrm{pH} 7 \cdot 2$ ). After processing, the fat samples were embedded in Paraplast plus (Sigma-Aldrich, St Louis, MO, USA), cut into $5 \mu \mathrm{m}$ thick slices and stained with haematoxylin and eosin for visualisation with light microscopy.

\section{Biochemical analyses and serum hormone concentrations}

Plasma was obtained by blood centrifugation (120 $\boldsymbol{g}$ for $15 \mathrm{~min})$ at room temperature and stored individually at $-20^{\circ} \mathrm{C}$ until analysis. Total cholesterol and TAG were measured by a colorimetric method (Bioclin, Belo Horizonte, Brazil). Fasting serum levels of insulin, leptin and resistin were measured by multiplex ELISA (Millipore, Billerica, MA, USA). Homeostatic model assessment of insulin resistance (HOMAIR) was calculated to assess peripheral insulin resistance, and homeostatic model assessment of $\beta$-cell function (HOMA- $\beta$ ) was calculated to assess the functional capacity of pancreatic $\beta$-cells ${ }^{(28)}$. The energy intake $(\mathrm{kJ} / \mathrm{d})$ :plasma leptin concentration $(\mathrm{ng} / \mathrm{ml})$ ratio was used to quantify endogenous leptin sensitivity ${ }^{(29)}$.

\section{Adipocyte morphometry}

The cross-sectional area of the adipocytes was determined in epididymal adipose tissue (visceral fat) using digital images (TIFF format, 36-bit colour, $1280 \times 1024$ pixels, LC Evolution camera, Olympus BX51 microscope) analysed with the software Image-Pro Plus version 7.0 (Media Cybernetics, Silver Spring, MD, USA). At least fifty adipocytes per animal ( $n$ 5) were randomly measured, totalling 250 adipocytes per group.

\section{Western blotting}

Expression of leptin in adipose tissue and Ob-Rb, NPY and POMC in the hypothalamus was detected by immunoblotting. About $100 \mathrm{mg}$ of epididymal adipose and hypothalamus tissue were harvested in ice-cold lysis buffer containing a protease inhibitor cocktail (Sigma-Aldrich). The supernatant fraction protein concentration was determined with a bicinchoninic acid (BCA) protein assay kit (Pierce, Rockford, IL, USA).
Protein $(10 \mu \mathrm{g}$ per sample) was denatured by boiling for $5 \mathrm{~min}$ and then separated by electrophoresis in $10 \%(\mathrm{w} / \mathrm{v})$ SDS-polyacrylamide for the hypothalamus or $12 \%(\mathrm{w} / \mathrm{v})$ SDS-polyacrylamide for the adipose tissue. A molecularweight marker (Bio-Rad, Hercules, CA, USA) was included on the gels to identify the molecular weights of the specific proteins of interest. The proteins were transferred to a nitrocellulose membrane and incubated for $1 \mathrm{~h}$ in a blocking solution containing $5 \%$ non-fat dry milk in 2-amino-2-hydroxymethyl-propane-1,3-diol (Tris)-buffered saline with $0.05 \%$ Tween ( $\mathrm{pH} 7 \cdot 4$ ) (TBS-T), followed by overnight incubation in TBS-T at $4^{\circ} \mathrm{C}$ with the primary anti-mouse Ob-R polyclonal antibody, anti-mouse NPY polyclonal antibody, anti-mouse POMC polyclonal antibody, anti-mouse leptin polyclonal antibody or anti-mouse $\beta$-actin monoclonal antibody. All primary antibodies were purchased from Santa Cruz Biotechnology (Santa Cruz, CA, USA). The membrane was then incubated for $1.5 \mathrm{~h}$ with horseradish peroxidase (HRP)-conjugated donkey anti-goat secondary antibody for Ob-R, HRP-conjugated goat anti-rabbit for NPY and POMC, HRP-conjugated donkey anti-rabbit for leptin and HRP-conjugated goat anti-mouse for $\beta$-actin in T-TBS. Immunoreactive bands were detected with ECL reagent (Amersham Biosciences, Piscataway, NJ, USA). The density ratios of the bands were measured using Image-Pro Plus software version 7.0 (Media Cybernetics).

\section{Statistical analysis}

Data are expressed as mean values with their standard errors. Differences between groups in the same generation or between the F1 and F2 generations were analysed using $t$ tests. Additionally, the body-weight data over time were analysed by mixed-model ANOVA. All statistical analyses were performed with GraphPad Prism Software (GraphPad Prism version 5.03 for Windows; GraphPad Software, San Diego, CA, USA). $P$ values $\leq 0.05$ were considered statistically significant.

\section{Results}

\section{Biometric results and adipocyte morphometry}

Analysis of both the F0 and F1 mothers found no differences in either the size $(n)$ or proportion of sexes (female/male) per litter (data not shown). However, the protein-restricted diet during pregnancy resulted in significant differences in the biometric parameters (BM and NAL) among the F1 generation during lactation. Specifically, the average $\mathrm{BM}$ of the LP1 offspring at birth was reduced by 39\% $(P<0 \cdot 0001)$ when compared with the NP1 offspring. However, by 4 weeks of age $(P=0.081)$ and until the end of the study $(P=0.7018)$, there were no differences in BM between the LP1 and NP1 mice. In contrast to the F1 generation, the BM of the LP2 group was not significantly different from that of the NP2 animals at birth $(P=0 \cdot 1494)$ or throughout the experiment ( $P=0.0878$ at 16 weeks old) (Fig. 1$)$. 

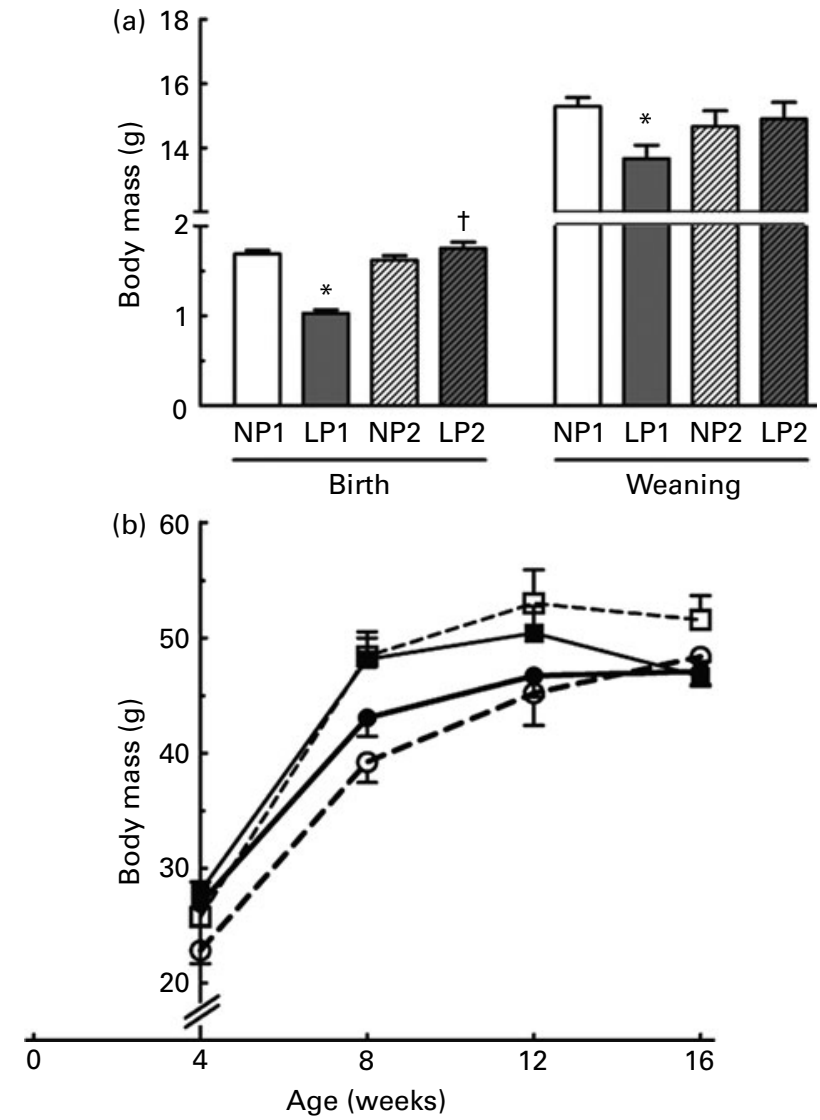

Fig. 1. (a) Body mass in mice at birth and at weaning. NP1, normal-protein diet first generation; LP1, low-protein diet first generation; NP2, normal-protein diet second generation; LP2, low-protein diet second generation. Values are means for five animals per group, with standard errors represented by vertical bars. * Mean value was significantly different from that of the normalprotein group of the same generation $(P<0.05 ; t$ test). † Mean value was significantly different from that of the $\mathrm{F} 1$ counterpart $(P<0.05 ; t$ test). (b) Evolution of body mass over time. (-๑-), NP1; (--O--), LP1 $(-\square-)$, NP2; (- - --), LP2. Values are means for five animals per group, with standard errors represented by vertical bars.

During lactation, all groups demonstrated a weekly BM gain that was statistically significant when analysed by mixedmodel ANOVA. In the post-weaning period, NP1 $(F=7 \cdot 160$; $P=0.0035)$ and NP2 $(F=8.595 ; P=0.0010)$ offspring gained weight weekly until they reached the age of 7 weeks, while the LP1 offspring ( $F=4.980 ; P=0.0013$ ) gained weight significantly until week 10 . By contrast, the weight gain of LP2 offspring $(F=5.659 ; P=0.0085)$ was more similar to that of the NP1 and NP2 offspring, which ceased by 7 weeks.

A comparison of the NAL between groups demonstrated that the LP1 mice were $10 \%$ shorter at birth than the NP1 mice $(\mathrm{NP} 1=3.08(\operatorname{sem} 0.04) \mathrm{cm} ; \mathrm{LP} 1=2.78(\operatorname{SEM} 0.07) \mathrm{cm}$; $P=0.0059)$. On the contrary, the NAL of the LP2 mice did not differ from that of the NP2 mice (NP2 $=3.18$ (SEM 0.03) $\mathrm{cm} ; \mathrm{LP} 2=3.26(\mathrm{SEM} 0.07) \mathrm{cm} ; P=0.3242)$ at birth. Furthermore, there was no difference in NAL among any of the groups at the end of the study $(\mathrm{NP} 1=11 \cdot 1(\operatorname{SEM} 0.07) \mathrm{cm}$, $\mathrm{LP} 1=11 \cdot 0(\mathrm{sem} 0.08) \mathrm{cm}, P=0.3744 ; \mathrm{NP} 2=11.3($ sem 0.08$)$ $\mathrm{cm}, \quad$ LP2 $=11.2 \quad($ SEM 0.08$) \quad \mathrm{cm}, \quad P=0.2215 ; \quad$ LP1 $v . \quad$ LP2, $P=0 \cdot 1503)$.
Although there were no significant differences in the BM among the groups at 16 weeks, the LP1 and LP2 groups demonstrated increases of 82 and $103 \%$, respectively, in body fat percentage as compared with the corresponding NP groups. This increase was further characterised as increases of 150 and $136 \%$ for visceral fat and 82 and $95 \%$ for subcutaneous fat in the LP1 and LP2 groups, respectively. The subcutaneous fat:visceral fat ratio was similar for both the LP1 and LP2 offspring (Table 1). In addition, the LP1 and LP2 offspring had 70 and $71 \%$ hypertrophy of adipocytes relative to the NP1 and NP2 offspring, respectively $(P<0 \cdot 0001)$ (Fig. 2).

\section{Lipid profile}

Altered lipid profiles were found in the LP groups from both generations. LP1 and LP2 offspring were hypercholesterolaemic, as indicated by a $26 \%$ increase in serum cholesterol. LP1 and LP2 mice also had increases of 55 and 114\% in serum TAG levels when compared with the NP1 and NP2 mice, respectively. Comparison of the two LP groups revealed an increase of $25 \%$ in serum TAG levels in the LP2 relative to the LP1 offspring (Table 1).

\section{Metabolic profile (glucose homeostasis and hormone concentrations)}

At the age of 16 weeks, LP1 and LP2 offspring showed an increase of 26 and $23 \%$, respectively, in fasting glycaemia relative to the corresponding NP mice. Serum insulin was also increased by 130 and $152 \%$ in the LP1 and LP2 offspring over the NP1 and NP2 offspring, respectively. No significant differences in glycaemia or insulinaemia were found between the LP1 and LP2 offspring (Table 1).

The OGTT revealed higher serum glucose levels in LP offspring than in NP offspring, quantified as an increase of $25 \%(P=0.0426)$ and $32 \%(P=0.0038)$ in the LP1 and LP2 offspring, respectively. This indicates glucose intolerance in the LP offspring, but no difference between the F1 and F2 generations $(P=0.4200)$ (Fig. 3). Furthermore, the IPITT demonstrated insulin resistance in LP offspring, measured as a $105 \%$ increase $(P<0.0001)$ in the area under the curve for the LP1 offspring and a $40 \%$ increase $(P=0.0035)$ for the LP2 mice when compared with the NP offspring (Fig. 3). Similar results were obtained for the HOMA-IR, with an increase of 230 and $256 \%$ for the LP1 and LP2 offspring, respectively (Table 1). According to the HOMA- $\beta$ results, LP1 offspring contained greater numbers of $\beta$-cells, which were increased by $66 \%$ relative to the NP1 and $63 \%$ relative to the LP2 mice (Table 1). Resistin levels were also increased by $44 \%$ in the LP1 and $56 \%$ in the LP2 when compared with the NP1 and NP2 offspring, respectively. There was no difference in resistin levels between the F1 and F2 offspring (Table 1). In summary, the differences encountered between the LP1 and LP2 offspring in the IPITT $(P=0.0003)$ and HOMA- $\beta$ $(P=0.0232)$ analyses suggest that insulin resistance is more pronounced in the LP1 than in the LP2 offspring. 
Table 1. Adiposity, biochemistry, hormones and food behaviour

(Mean values with their standard errors)

\begin{tabular}{|c|c|c|c|c|c|c|c|c|c|c|c|}
\hline \multirow[b]{2}{*}{ Data } & \multicolumn{2}{|c|}{ NP1 $(n 5)$} & \multicolumn{2}{|c|}{ LP1 ( $n$ 5) } & \multirow[b]{2}{*}{$P$} & \multicolumn{2}{|c|}{ NP2 $(n 5)$} & \multicolumn{2}{|c|}{ LP2 ( $n$ 5) } & \multirow[b]{2}{*}{$P$} & \multirow{2}{*}{$\begin{array}{c}P \\
(\mathrm{~F} 1 \text { v. F2) }\end{array}$} \\
\hline & Mean & SEM & Mean & SEM & & Mean & SEM & Mean & SEM & & \\
\hline \multicolumn{12}{|l|}{ Adiposity } \\
\hline Body fat (\%) & 3.62 & 0.59 & $6 \cdot 61^{\star}$ & 0.87 & 0.02 & 2.57 & 0.60 & $5 \cdot 22^{*}$ & 0.91 & 0.04 & 0.30 \\
\hline Visceral fat (g) & 0.58 & 0.09 & $1.45^{\star}$ & 0.25 & 0.01 & 0.50 & 0.13 & $1 \cdot 17^{\star}$ & 0.23 & 0.03 & 0.43 \\
\hline Subcutaneous fat $(\mathrm{g})$ & 0.11 & 0.02 & $0 \cdot 20^{*}$ & 0.03 & 0.04 & $0 \cdot 13$ & 0.04 & $0 \cdot 26^{\star}$ & 0.03 & 0.03 & 0.20 \\
\hline $\begin{array}{l}\text { Subcutaneous fat:visceral } \\
\text { fat ratio }(\mathrm{g} / \mathrm{g})\end{array}$ & 0.20 & 0.04 & 0.17 & 0.01 & 0.49 & 0.20 & 0.03 & 0.18 & 0.01 & 0.63 & 0.50 \\
\hline \multicolumn{12}{|l|}{ Biochemistry and hormones } \\
\hline Cholesterol (mg/l) & 1020 & $35 \cdot 6$ & $1280^{*}$ & $32 \cdot 6$ & 0.0007 & 990 & $24 \cdot 0$ & $1250^{\star}$ & $28 \cdot 4$ & $<0.0001$ & 0.51 \\
\hline TAG $(\mathrm{mg} / \mathrm{l})$ & 430 & $24 \cdot 8$ & $670^{*}$ & $31 \cdot 3$ & 0.0003 & 390 & $17 \cdot 5$ & $830^{*} \dagger$ & $23 \cdot 1$ & $<0.0001$ & 0.003 \\
\hline Fasting glucose $(\mathrm{mg} / \mathrm{l})$ & 1290 & $60 \cdot 1$ & $1630^{*}$ & $58 \cdot 9$ & 0.004 & 1170 & $57 \cdot 7$ & $1440^{*}$ & $97 \cdot 7$ & 0.04 & 0.13 \\
\hline Insulin $(\mu \mathrm{g} / \mathrm{l})$ & 0.64 & 0.08 & $1.48^{\star}$ & 0.19 & 0.004 & 0.51 & 0.04 & $1 \cdot 28^{*}$ & 0.31 & 0.04 & 0.61 \\
\hline HOMA-IR & $4 \cdot 36$ & 0.57 & $14 \cdot 39^{*}$ & $2 \cdot 19$ & 0.002 & 3.66 & 0.42 & $13 \cdot 06^{\star}$ & $3 \cdot 28$ & 0.02 & 0.75 \\
\hline HOMA- $\beta$ & 84.01 & $5 \cdot 83$ & $139 \cdot 40^{*}$ & $15 \cdot 62$ & 0.01 & $86 \cdot 01$ & 6.58 & $85 \cdot 61 \dagger$ & $11 \cdot 19$ & 0.98 & 0.02 \\
\hline Resistin (ng/ml) & 1.27 & $0 \cdot 18$ & $1.83^{*}$ & 0.10 & 0.03 & 1.35 & 0.16 & $2 \cdot 11^{\star}$ & 0.25 & 0.03 & 0.34 \\
\hline Leptin (ng/ml) & $1 \cdot 84$ & $0 \cdot 16$ & $5 \cdot 86^{*}$ & 0.74 & 0.0007 & 1.55 & 0.12 & $10 \cdot 97^{\star} \dagger$ & 0.78 & $<0.0001$ & 0.002 \\
\hline \multicolumn{12}{|l|}{ Food behaviour } \\
\hline Food intake (g/d) & 5.00 & 0.23 & 4.78 & 0.32 & 0.59 & 5.74 & 0.38 & $5.97 \dagger$ & 0.32 & 0.66 & 0.02 \\
\hline $\begin{array}{l}\text { Food intake adjusted for } \\
\text { body mass }(\mathrm{g} / \mathrm{g})\end{array}$ & $11 \cdot 64$ & 0.43 & 11.91 & 0.56 & 0.71 & $12 \cdot 68$ & 0.60 & $12 \cdot 61$ & 0.41 & 0.93 & 0.32 \\
\hline $\begin{array}{l}\text { Energy intake:leptin ratio } \\
\quad(\mathrm{kJ} / \mathrm{d} \text { per } \mathrm{ng} / \mathrm{ml})\end{array}$ & 0.06 & 0.01 & $0.02^{*}$ & 0.001 & $0 \cdot 001$ & 0.06 & 0.01 & $0.02^{*}$ & 0.003 & 0.002 & 0.06 \\
\hline
\end{tabular}

NP1, normal-protein diet first generation; LP1, low-protein diet first generation; NP2, normal-protein diet second generation; LP2, low-protein diet second generation; F1, first generation; F2, second generation; HOMA-IR, homeostatic model assessment of insulin resistance; HOMA- $\beta$, homeostatic model assessment of $\beta$-cell function.

* Mean value was significantly different from that of the normal-protein group of the same generation ( $t$ test).

† Mean value was significantly different from that of the F1 counterpart $(t$ test).

\section{Food intake and serum leptin}

Food intake, when adjusted for BM, was not significantly different among the groups (Table 1). However, the concentration of serum leptin in the LP1 and LP2 offspring was increased by 218 and $608 \%$, respectively, relative to the NP1 and NP2 offspring, indicating a state of leptin resistance in the LP offspring. Interestingly, serum leptin in the LP2 offspring was $87 \%$ higher than the level in the LP1 offspring (Table 1). With the analysis of energy intake in relation to serum leptin levels, the present study demonstrates that both the LP1 and LP2 offspring showed a 200\% decrease in endogenous leptin sensitivity, as compared with the respective NP offspring. No differences were found between the F1 and F2 groups in endogenous leptin sensitivity, however (Table 1).

\section{Leptin signalling in the adipose tissue and in the hypothalamus}

LP1 and LP2 offspring, when compared with NP1 and NP2 offspring, had respective increases of $33 \%(P=0.0067)$ and $34 \%(P=0.0053)$ in leptin expression in visceral adipose tissue, without differences between the generations $(P=0.5629)$. No differences were found in $\beta$-actin expression between the groups (LP1, $P=0.9791$; LP2, $P=0.0853$; LP1 $v$. LP2, $P=0.0914$; NP1 $v$. NP2, $P=0.7069$ ) (Fig. 4). Despite the differences in adipose leptin levels, no differences were observed in hypothalamic leptin receptor expression among the groups (LP1, $P=0.8227$; LP2, $P=0.9877$; LP1 $v$. LP2, $P=0.5906$ ) (Fig. 4). Regarding the expression of hypothalamic neuropeptides, similar increases were observed for the expression of NPY in both LP groups $(P=0 \cdot 4715)$; specifically, NPY was increased by $62 \%(P=0.0351)$ in LP1 and $57 \%$ $(P=0.0114)$ in LP2 when compared with NP1 and NP2 offspring. POMC, however, was decreased by $105 \%$ $(P=0.0306)$ in the LP1 group only and remained unchanged in the LP2 group relative to the NP2 offspring $(P=0.9905)$. The LP2 POMC level, therefore, differed significantly from the LP1 POMC level ( $P=0.0284$ ) (Fig. 5). Again, no differences were observed for $\beta$-actin expression between the groups (LP1, $P=0 \cdot 1997$; LP2, $P=0 \cdot 1076$; LP1 $v$. LP2, $P=0 \cdot 1710$; NP1 v. NP2, $P=0 \cdot 8615)$.

\section{Discussion}

In the present study, we observed a lower birth weight for F1 generation pups born to mothers fed a low-protein diet, and this nutrient restriction in F1 mothers was further transferred to the F2 generation. LP1 mice showed intrauterine growth retardation, clearly evident at birth, but in the post-weaning period we observed compensatory growth during the lactation period and extended BM gain in these animals (until week 10), characterising a catch-up in BM. Furthermore, the two generations (F1 and F2) subsequently developed progressive glucose intolerance, insulin resistance and marked adipocyte hypertrophy with significant alterations in the central mechanisms of leptin signalling characterised by leptin resistance later in life.

Adipocyte development begins in the fetus and, in contrast to other tissues whose growth ceases late in juvenile 

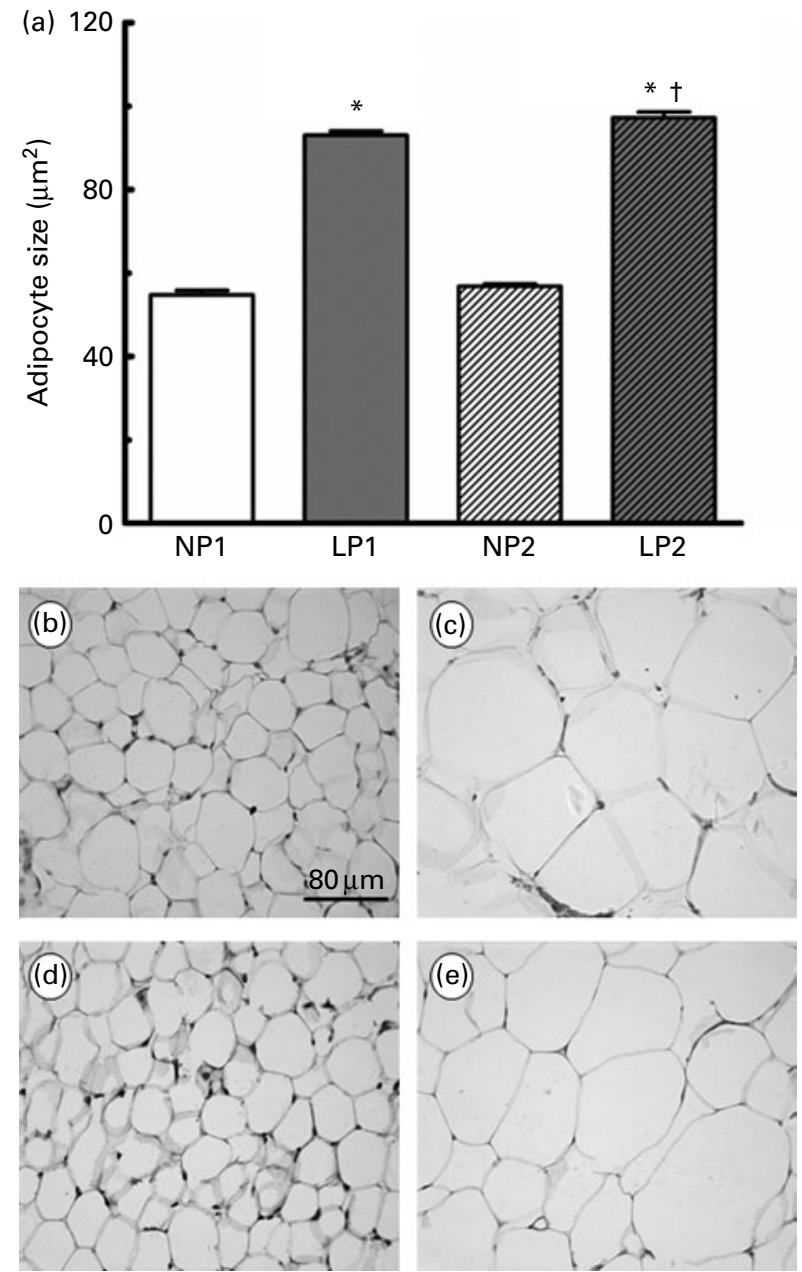

Fig. 2. (a) Mean cross-sectional area of adipocytes. NP1, normal-protein diet first generation; LP1, low-protein diet first generation; NP2, normal-protein diet second generation; LP2, low-protein diet second generation. Values are means for five animals per group, with standard errors represented by vertical bars. * Mean value was significantly different from that of the normalprotein group of the same generation $(P<0.05 ; t$ test). † Mean value was significantly different from that of the $\mathrm{F} 1$ counterpart $(P<0.05 ; t$ test). (b) NP1, (c) LP1, (d) NP2 and (e) LP2 photomicrographs of adipocyte tissue (haematoxylin and eosin staining).

development, has the capacity for 'unlimited' growth $^{(30)}$. Previous studies have demonstrated that this hypertrophic catch-up phenotype is likely to predispose individuals to decreased adipose tissue insulin sensitivity, enhanced secretion of pro-inflammatory adipokines that induce insulin resistance in all insulin-sensitive tissue ${ }^{(31,32)}$ and/or spillover of lipids to non-adipocytes (with ectopic lipotoxicity). These effects exacerbate insulin resistance in insulin-sensitive tissues and consequently increase systemic insulin resistance and impair glucose tolerance ${ }^{(33)}$. The present study identified an increase in blood insulin, HOMA-IR, HOMA- $\beta$ and resistin levels, as well as altered OGTT and IPITT in both the F1 and F2 generations. This is a strong indication that maternal protein restriction leads to alterations in the glucose metabolism of pups, which can be transmitted across generations. In accordance with the previous study, no effect on food intake by the pups was observed ${ }^{(34)}$. Thus, the higher adiposity observed in LP offspring was probably not due to a difference in energy intake but rather to the thrifty phenotype of these animals ${ }^{(35)}$

Additionally, all the described dysfunctions converge to alter overall lipid metabolism, possibly due to changes in the expression of genes involved in fat metabolism, insulin signalling and ageing ${ }^{(36)}$. These changes lead to an altered lipid profile with high levels of cholesterol and TAG, as were found in the LP1 and LP2 offspring.

Alterations in adiposity are especially important when considering that energy balance is regulated by feedback from peripheral hormonal and metabolic signals on a central circuit mediated by the hypothalamus ${ }^{(4)}$. In these processes, both leptin and insulin control nutritional status and energy storage levels by modulating the expression of neuropeptides, such as NPY and $\alpha-\mathrm{MSH}$ (a derivative of POMC) in the hypothalamic nuclei $^{(37,38)}$. Indeed, the hypothalamus plays a pivotal role in programming fetal and neonatal development. In rodents, evidence suggests that hypothalamic 'malprogramming' begins in utero and continues in early postnatal life (suckling
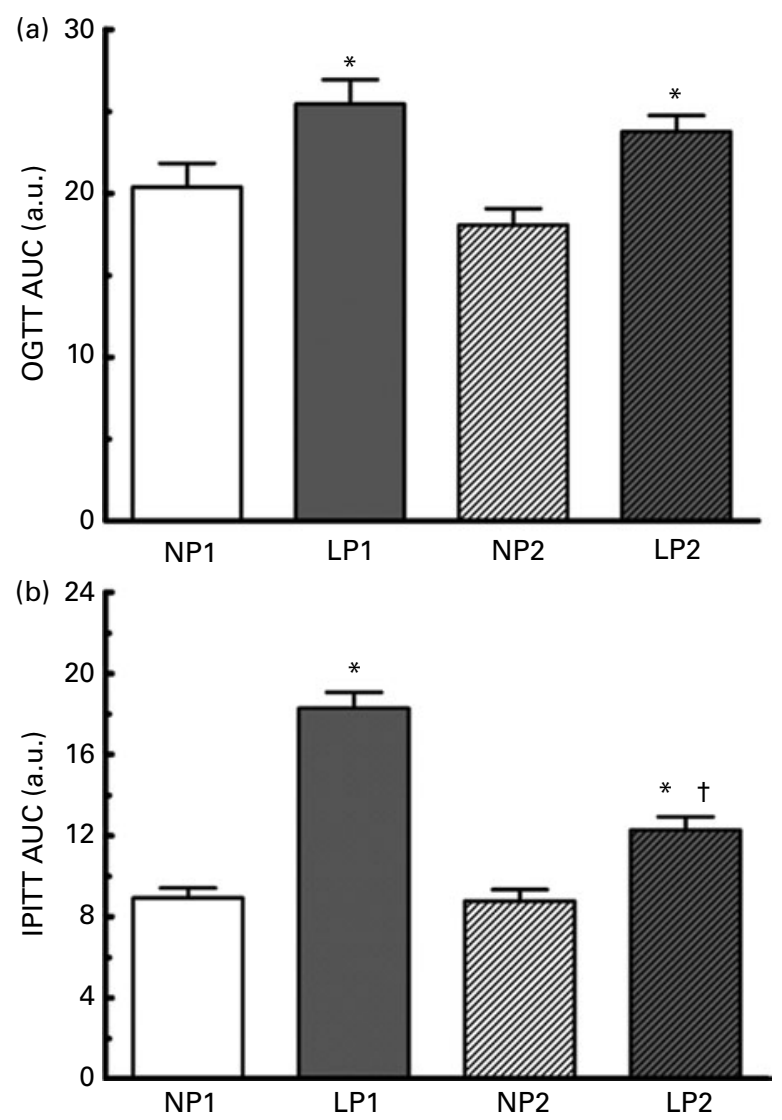

Fig. 3. Glucose metabolism, measured by (a) the oral glucose tolerance test (OGTT) and (b) the intraperitoneal insulin tolerance test (IPITT). AUC, area under curve; a.u., arbitrary units; NP1, normal-protein diet first generation; LP1, low-protein diet first generation; NP2, normal-protein diet second generation; LP2, low-protein diet second generation. Values are means for five animals per group, with standard errors represented by vertical bars. * Mean value was significantly different from that of the normal-protein group of the same generation $(P<0.05 ; t$ test). † Mean value was significantly different from that of the $\mathrm{F} 1$ counterpart $(P<0.05 ; t$ test $)$. 
(a) $\beta$-Actin

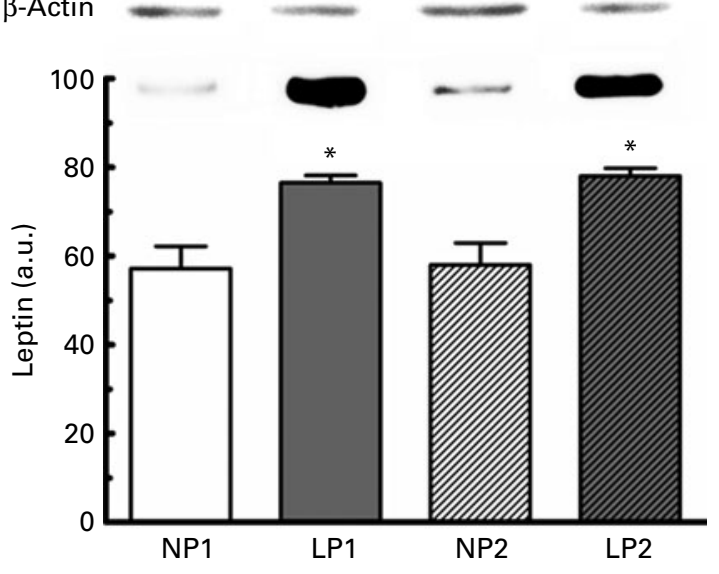

(b)

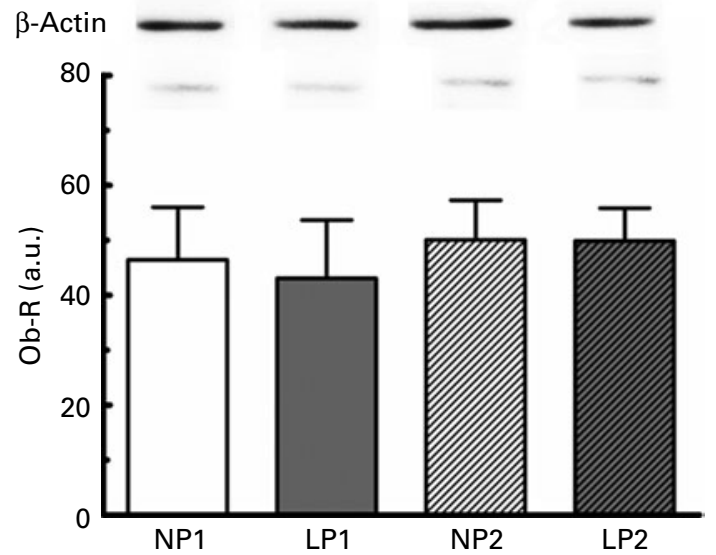

Fig. 4. Western blotting analyses for (a) leptin expression in visceral adipose tissue and (b) hypothalamic leptin receptor Ob-R expression. a.u., Arbitrary units; NP1, normal-protein diet first generation; LP1, low-protein diet first generation; NP2, normal-protein diet second generation; LP2, low-protein diet second generation. Values are means for five animals per group, with standard errors represented by vertical bars. * Mean value was significantly different from that of the normal-protein group of the same generation $(P<0.05 ; t$ test $)$.

period), leading to disturbed hypothalamic organisation and, consequently, long-lasting dysfunction in adulthood $^{(26)}$. It was recently demonstrated that maternal protein restriction affects brain development in utero by significantly decreasing the expression of sixteen genes involved in DNA methylation, cell-cycle proliferation, developmental processes and synaptogenesis $^{(10)}$.

Here, maternal protein restriction led to peripheral and sequential central insulin and leptin resistance. Peripheral leptin resistance was evaluated by calculating the energy intake:plasma leptin concentration ratio. Although no differences were found in energy intake, a disparity between leptin levels and energy homeostasis was identified. This result is evidence of an unaltered energy intake despite the elevated leptin levels, indicating an alteration in energy homeostasis. Leptin resistance at the central level may occur because leptin fails to cross the blood-brain barrier, hypothalamic receptors are down-regulated or there are abnormalities in the leptin receptor signalling pathway ${ }^{(39)}$. To identify the mechanism of leptin resistance in the LP offspring, Ob-Rb, NPY and POMC levels were measured. Arcuate nucleus neurons expressing NPY co-express leptin and insulin receptors ${ }^{(40)}$, both of which inhibit the expression of $\mathrm{NPY}^{(41)}$. POMC is the precursor of anorexigenic melanocortins $^{(42)} \cdot \alpha-\mathrm{MSH}$ is believed to be crucial for the regulation of food intake and body-weight homeostasis, and leptin also stimulates the expression of $\mathrm{POMC}^{(43)}$.

In the present study, central leptin resistance was demonstrated as an increase in leptin expression in adipose tissue, accompanied by dysfunction in the modulation of the hypothalamic neuropeptides in adult offspring from both the F1 and F2 generations. It is important to emphasise that very few experimental data are available regarding the long-term consequences of maternal protein restriction on neuroendocrine peptide expression in adult offspring. In a hyperleptinaemic state, the mRNA expression of $\mathrm{Ob}-\mathrm{Rb}$ in the hypothalamus has been shown to increase at first, but it then decreases in the presence of continuous leptin stimulation. Consequently, leptin signalling in the hypothalamus is inhibited despite elevated plasma levels ${ }^{(29,44)}$. High levels of leptin are presumed to signal positive energy balance and

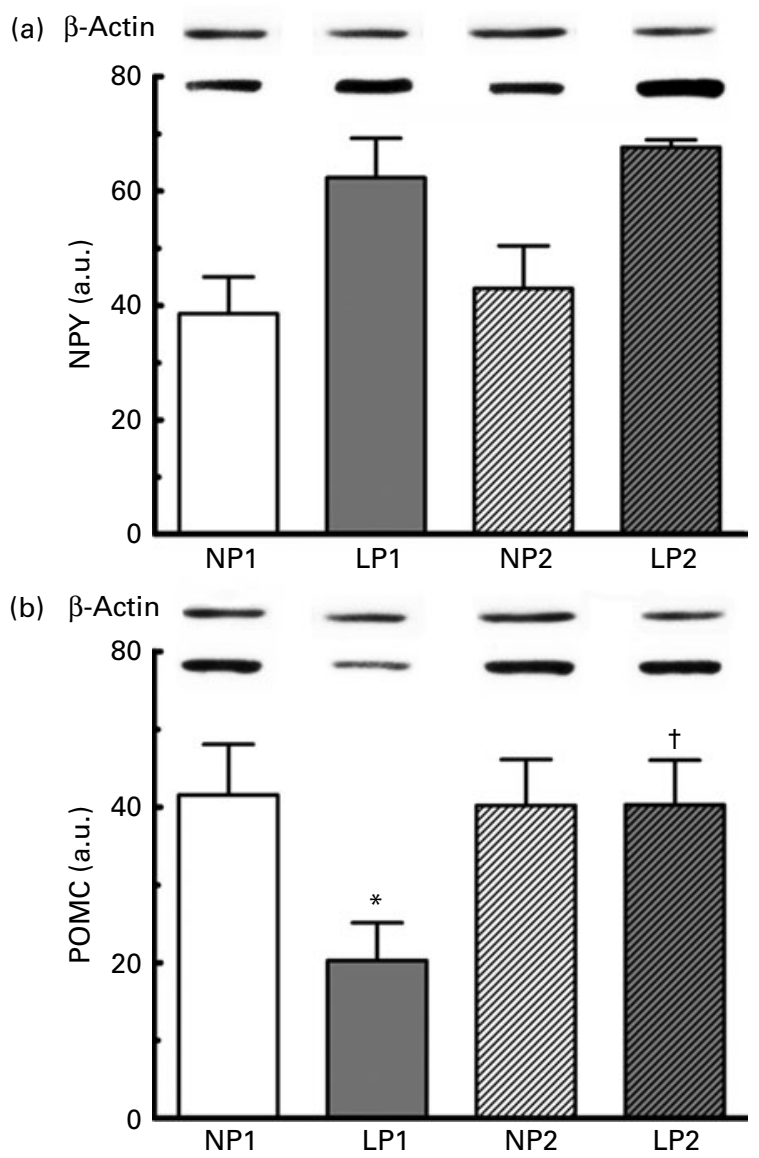

Fig. 5. Western blotting analyses for (a) hypothalamic neuropeptide Y (NPY) expression and (b) hypothalamic pro-opiomelanocortin (POMC) expression. a.u., Arbitrary units; NP1, normal-protein diet first generation; LP1, low-protein diet first generation; NP2, normal-protein diet second generation; LP2, low-protein diet second generation. Values are means for five animals per group, with standard errors represented by vertical bars. * Mean value was significantly different from that of the normal-protein group of the same generation $(P<0.05 ; t$ test). † Mean value was significantly different from that of the F1 counterpart $(P<0.05 ; t$ test). 
counteract this state through two pathways; the expression of anorexigenic genes, such as POMC, is increased in response to leptin, whereas the expression of orexigenic genes, such as $\mathrm{NPY}$, is decreased ${ }^{(26)}$. The LP offspring in the present study showed no changes in Ob-Rb expression, although they did demonstrate alterations in the expression of other hypothalamic neuropeptides. Therefore, the high plasma leptin levels observed in the pups whose mothers were protein-restricted were not sufficient to diminish NPY or to increase POMC in these animals. Furthermore, a high expression of NPY and a low expression of POMC were observed in F1 adult offspring. A high expression of NPY was also observed in the F2 generation, while the expression of POMC was unchanged relative to the NP offspring.

The present study reinforces the suggestion, which is gaining support in the literature, that nutrition in fetal and early life perpetually makes an impact on energy balance systems. The failure of hyperleptinaemia to affect NPY mRNA levels in the LP offspring suggests that NPY neurons are less sensitive to leptin suppression, which is in agreement with a recent description of NPY neuronal resistance ${ }^{(45)}$. Alterations in the NPY neurons of fetal and postnatal offspring support the suggestion that the NPY system is a key target of programming, possibly controlling the body-weight set point ${ }^{(46,47)}$. Additionally, increases in NPY expression may be the result of inhibited leptin signalling due to a reduced activation of STAT-3 or an increased expression of suppressor of cytokine signalling-3 (SOCS-3), which inhibits leptin signalling ${ }^{(48)}$.

In the LP2 offspring, leptin resistance could be the result of multiple factors, including epigenetic mechanisms and possible maternal hyperglycaemia. It has been proposed that physiological and metabolic alterations in the maternal organism that result in intra-uterine undernutrition, combined with the metabolic stress from pregnancy, may result in metabolic intergenerational programming ${ }^{(49)}$. In a recent study, it was observed that altered maternal glucose contributes to leptin resistance in offspring without reducing the number of leptin receptors ${ }^{(50)}$. Importantly, hyperglycaemic mothers give birth to offspring with 'malorganisation' of the hypothalamic neurons, characterised by an increase in NPY and Agouti-related peptide (AgRP) neurons and a decrease in MSH neurons with no change in POMC expression at weaning ${ }^{(51)}$. The epigenetic theory proposes that developmental programming occurs through changes in gene expression without alterations in the DNA sequence ${ }^{(52)}$ due to DNA methylation $^{(53)}$ or changes in the terminal regions of histones ${ }^{(54)}$. Metabolic programming can also be promoted by alterations in mitochondrial DNA, leading to the transmission of altered phenotypes to subsequent generations through the maternal lineage ${ }^{(55)}$.

In conclusion, the findings presented here allow us to conclude that severe maternal protein restriction promotes metabolic programming characterised by increased adiposity with alterations in the lipid profile, glucose intolerance and insulin resistance due to a disruption in the adipoinsular axis and hypothalamic leptin resistance in both the F1 and F2 generations.

\section{Acknowledgements}

The authors are grateful to Mrs Thatiany Marinho for her technical assistance. The authors disclose no financial interest in or commercial sponsorship of the study. This research was supported by grants to A. P. M. from the National Council for Scientific and Technological Development (CNPq; MCT/CNPq 14/2009) and to C. A. M.-de-L. from CAPES (Coordenação de Aperfeiçoamento de Pessoal de Nível Superior) (AUX-PEPRODOC-2043/2008). N. P.-S. and E. D. C. F. performed the experiments, analysed the data and wrote the paper. A. P.-M. designed the experiment, analysed the data and wrote the paper. C. A. M.-de-L. supervised the project.

\section{References}

1. Kirk SL, Samuelsson AM, Argenton M, et al. (2009) Maternal obesity induced by diet in rats permanently influences central processes regulating food intake in offspring. PLoS One 4, e5870.

2. Muhlhausler BS, Adam CL \& McMillen IC (2008) Maternal nutrition and the programming of obesity: the brain. Organogenesis 4, 144-152.

3. Parente LB, Aguila MB \& Mandarim-de-Lacerda CA (2008) Deleterious effects of high-fat diet on perinatal and postweaning periods in adult rat offspring. Clin Nutr 27, 623-634.

4. Cripps RL, Martin-Gronert MS, Archer ZA, et al. (2009) Programming of hypothalamic neuropeptide gene expression in rats by maternal dietary protein content during pregnancy and lactation. Clin Sci (Lond) 117, 85-93.

5. Chen H, Simar D \& Morris MJ (2009) Hypothalamic neuroendocrine circuitry is programmed by maternal obesity: interaction with postnatal nutritional environment. PLOS One 4, e6259.

6. Page KC, Malik RE, Ripple JA, et al. (2009) Maternal and postweaning diet interaction alters hypothalamic gene expression and modulates response to a high-fat diet in male offspring. Am J Physiol Regul Integr Comp Physiol 297, R1049-R1057.

7. Delahaye F, Breton C, Risold PY, et al. (2008) Maternal perinatal undernutrition drastically reduces postnatal leptin surge and affects the development of arcuate nucleus proopiomelanocortin neurons in neonatal male rat pups. Endocrinology 149, 470-475.

8. Breton C, Lukaszewski MA, Risold PY, et al. (2009) Maternal prenatal undernutrition alters the response of POMC neurons to energy status variation in adult male rat offspring. Am J Physiol Endocrinol Metab 296, E462-E472.

9. Orozco-Solis R, Matos RJ, Guzman-Quevedo O, et al. (2010) Nutritional programming in the rat is linked to long-lasting changes in nutrient sensing and energy homeostasis in the hypothalamus. PLoS One 5, e13537.

10. Coupe B, Amarger V, Grit I, et al. (2010) Nutritional programming affects hypothalamic organization and early response to leptin. Endocrinology 151, 702-713.

11. Bouret SG \& Simerly RB (2006) Developmental programming of hypothalamic feeding circuits. Clin Genet 70, 295-301.

12. Bouret SG (2009) Early life origins of obesity: role of hypothalamic programming. I Pediatr Gastroenterol Nutr 48, Suppl. 1, S31-S38.

13. Huang XF, Xin X, McLennan P, et al. (2004) Role of fat amount and type in ameliorating diet-induced obesity: insights at the level of hypothalamic arcuate nucleus leptin 
receptor, neuropeptide $\mathrm{Y}$ and pro-opiomelanocortin mRNA expression. Diabetes Obes Metab 6, 35-44.

14. Williams G, Bing C, Cai XJ, et al. (2001) The hypothalamus and the control of energy homeostasis: different circuits, different purposes. Physiol Behav 74, 683-701.

15. Friedman JM \& Halaas JL (1998) Leptin and the regulation of body weight in mammals. Nature 395, 763-770.

16. Enriori PJ, Evans AE, Sinnayah P, et al. (2006) Leptin resistance and obesity. Obesity (Silver Spring) 14, Suppl. 15, $254-258$

17. Fam BC, Morris MJ, Hansen MJ, et al. (2007) Modulation of central leptin sensitivity and energy balance in a rat model of diet-induced obesity. Diabetes Obes Metab 9, 840-852.

18. Bjorbaek C \& Kahn BB (2004) Leptin signaling in the central nervous system and the periphery. Recent Prog Horm Res 59, 305-331.

19. Kamiji MM \& Inui A (2007) Neuropeptide Y receptor selective ligands in the treatment of obesity. Endocr Rev $\mathbf{2 8}$, 664-684.

20. Schwartz MW, Woods SC, Porte D Jr, et al. (2000) Central nervous system control of food intake. Nature 404, 661-671.

21. Munzberg H \& Myers MG Jr (2005) Molecular and anatomical determinants of central leptin resistance. Nat Neurosci 8, 566-570.

22. Pinheiro AR, Salvucci ID, Aguila MB, et al. (2008) Protein restriction during gestation and/or lactation causes adverse transgenerational effects on biometry and glucose metabolism in F1 and F2 progenies of rats. Clin Sci (Lond) 114, 381-392.

23. Reeves PG, Nielsen FH \& Fahey GC Jr (1993) AIN-93 purified diets for laboratory rodents: final report of the American Institute of Nutrition ad hoc writing committee on the reformulation of the AIN-76A rodent diet. $J$ Nutr 123, 1939-1951.

24. Fernandes-Santos C, Carneiro RE, de Souza Mendonca L, et al. (2009) Pan-PPAR agonist beneficial effects in overweight mice fed a high-fat high-sucrose diet. Nutrition $\mathbf{2 5}$, $818-827$

25. Fraulob JC, Ogg-Diamantino R, Fernandes-Santos C, et al. (2010) A mouse model of metabolic syndrome: insulin resistance, fatty liver and non-alcoholic fatty pancreas disease (NAFPD) in C57BL/6 mice fed a high fat diet. J Clin Biochem Nutr 46, 212-223.

26. Sellayah D, Sek K, Anthony FW, et al. (2008) Appetite regulatory mechanisms and food intake in mice are sensitive to mismatch in diets between pregnancy and postnatal periods. Brain Res 1237, 146-152.

27. Frontini A, Bertolotti P, Tonello C, et al. (2008) Leptindependent STAT3 phosphorylation in postnatal mouse hypothalamus. Brain Res 1215, 105-115.

28. Matthews DR, Hosker JP, Rudenski AS, et al. (1985) Homeostasis model assessment: insulin resistance and $\beta$-cell function from fasting plasma glucose and insulin concentrations in man. Diabetologia 28, 412-419.

29. Lin S, Storlien LH \& Huang XF (2000) Leptin receptor, NPY, POMC mRNA expression in the diet-induced obese mouse brain. Brain Res $\mathbf{8 7 5}, 89-95$.

30. Gimeno RE \& Klaman LD (2005) Adipose tissue as an active endocrine organ: recent advances. Curr Opin Pharmacol 5, 122-128.

31. Slawik M \& Vidal-Puig AJ (2007) Adipose tissue expandability and the metabolic syndrome. Genes Nutr 2, 41-45.

32. Isganaitis E, Jimenez-Chillaron J, Woo M, et al. (2009) Accelerated postnatal growth increases lipogenic gene expression and adipocyte size in low-birth weight mice. Diabetes $\mathbf{5 8}$, 1192-1200.
33. Dulloo AG (2009) Adipose tissue plasticity in catchup-growth trajectories to metabolic syndrome: hyperplastic versus hypertrophic catch-up fat. Diabetes 58, 1037-1039.

34. Bol VV, Delattre AI, Reusens B, et al. (2009) Forced catch-up growth after fetal protein restriction alters the adipose tissue gene expression program leading to obesity in adult mice. Am J Physiol Regul Integr Comp Physiol 297, R291-R299.

35. Hales CN \& Barker DJ (2001) The thrifty phenotype hypothesis. Br Med Bull 60, 5-20.

36. Erhuma A, Bellinger L, Langley-Evans SC, et al. (2007) Prenatal exposure to undernutrition and programming of responses to high-fat feeding in the rat. Br J Nutr $\mathbf{9 8}$, 517-524.

37. Niswender KD, Baskin DG \& Schwartz MW (2004) Insulin and its evolving partnership with leptin in the hypothalamic control of energy homeostasis. Trends Endocrinol Metab 15, 362-369.

38. Arora S \& Anubhuti (2006) Role of neuropeptides in appetite regulation and obesity - a review. Neuropeptides $\mathbf{4 0}$, $375-401$.

39. Sahu A (2004) Minireview: a hypothalamic role in energy balance with special emphasis on leptin. Endocrinology 145, 2613-2620.

40. Woods SC \& Seeley RJ (2001) Insulin as an adiposity signal. Int J Obes Relat Metab Disord 25, Suppl. 5, 35-38.

41. Korner J, Savontaus E, Chua SC Jr, et al. (2001) Leptin regulation of Agrp and Npy mRNA in the rat hypothalamus. J Neuroendocrinol 13, 959-966.

42. Wilkinson CW (2006) Roles of acetylation and other post-translational modifications in melanocortin function and interactions with endorphins. Peptides 27, 453-471.

43. Ellacott KL \& Cone RD (2006) The role of the central melanocortin system in the regulation of food intake and energy homeostasis: lessons from mouse models. Philos Trans $R$ Soc Lond B Biol Sci 361, 1265-1274.

44. Wilsey J \& Scarpace PJ (2004) Caloric restriction reverses the deficits in leptin receptor protein and leptin signaling capacity associated with diet-induced obesity: role of leptin in the regulation of hypothalamic long-form leptin receptor expression. J Endocrinol 181, 297-306.

45. Ikenasio-Thorpe BA, Breier BH, Vickers MH, et al. (2007) Prenatal influences on susceptibility to diet-induced obesity are mediated by altered neuroendocrine gene expression. $J$ Endocrinol 193, 31-37.

46. Terroni PL, Anthony FW, Hanson MA, et al. (2005) Expression of agouti-related peptide, neuropeptide Y, proopiomelanocortin and the leptin receptor isoforms in fetal mouse brain from pregnant dams on a protein-restricted diet. Brain Res Mol Brain Res 140, 111-115.

47. Lauzurica N, Garcia-Garcia L, Pinto S, et al. (2010) Changes in NPY and POMC, but not serotonin transporter, following a restricted feeding/repletion protocol in rats. Brain Res 1313, 103-112.

48. Munzberg H, Flier JS \& Bjorbaek C (2004) Region-specific leptin resistance within the hypothalamus of diet-induced obese mice. Endocrinology 145, 4880-4889.

49. Zambrano E (2009) The transgenerational mechanisms in developmental programming of metabolic diseases (article in Chinese). Rev Invest Clin 61, 41-52.

50. Liu HH, Zhang YL \& Yang HX (2009) Intrauterine hyperglycemia and leptin resistance of offsprings (article in Chinese). Zhonghua Fu Chan Ke Za Zhi 44, 841-845.

51. Franke K, Harder T, Aerts L, et al. (2005) 'Programming' of orexigenic and anorexigenic hypothalamic neurons in offspring of treated and untreated diabetic mother rats. Brain Res 1031, 276-283. 
52. Devaskar SU \& Raychaudhuri S (2007) Epigenetics - a science of heritable biological adaptation. Pediatr Res $\mathbf{6 1}$, $1 \mathrm{R}-4 \mathrm{R}$.

53. Holliday R (1989) DNA methylation and epigenetic mechanisms. Cell Biophys 15, 15-20.

54. Waterland RA \& Jirtle RL (2004) Early nutrition, epigenetic changes at transposons and imprinted genes, and enhanced susceptibility to adult chronic diseases. Nutrition 20, 63-68.

55. Zambrano E, Martinez-Samayoa PM, Bautista CJ, et al. (2005) Sex differences in transgenerational alterations of growth and metabolism in progeny (F2) of female offspring (F1) of rats fed a low protein diet during pregnancy and lactation. J Physiol 566, 225-236. 